\title{
TWO NEW SPECIES OF COELIGETES JACOBY FROM \\ MALAYSIA (COLEOPTERA, CHRYSOMELIDAE, GALERUCINAE)
}

\author{
By Mohamed S. Mohamedsaid \\ Centre for Insect Systematics \\ Universiti Kebangsaan Malaysia, 43600 Bangi, Malaysia
}

\begin{abstract}
Coeligetes borneensis, n.sp. and Coeligetes wilcoxi, n.sp. are described from Malaysia. The presence of the genus in Malaysia is a new record. A key to Malaysian species is provided.

\section{INTRODUCTION}

The genus Coeligetes was established by Jacoby in 1884 with Coeligetes submetallica as the type species (by monotypy). Previously unknown from Malaysia, this paper reports that the genus is represented by three species. Two of these are herein described as new-Coeligetes borneensis, n.sp. and Coeligetes wilcoxi, n.sp. The latter is also recorded for Indonesia, from a specimen in the collection of Museum of Comparative Zoology (MCZ), Harvard University, USA. Holotypes are deposited in the Centre for Insect Systematics, Universiti Kebangsaan Malaysia, Bangi (UKM).

Coeligetes can be distinguished from other genera in the Galerucinae by the following combination of characters: dorsal surfaces glabrous; pronotum convex, transverse, twice as broad as long, the anterior, posterior and lateral borders margined; epipleuron extending to apical fourth of elytron; anterior coxal cavity closed posteriorly; posterior tarsus with first segment as long as the following segments combined; tarsal claws appendiculate; male with the apical sternite trilobed; female with the apical sternite deeply emarginate at apex.
\end{abstract}

Manuscript received 20 January 1994. 
Key to the species of Coeligetes

1. Elytra green, rugose, densely covered with large punctures. Legs reddish brown, except tibiae with black streak at the outer sides. In male, each posterior trochanter bearing a spine half as long as femur; apical sternite (Fig. 1a) with median lobe oblong, its surface deeply concave; aedeagus as in Fig. 2a. Length $11.5-13.5 \mathrm{~mm}$ borneensis, new species Elytra not green; surface covered with small punctures not rugose. In male, posterior trochanters without spines .2

2. Elytra brownish, black on lateral, sutural and apical margins. In male, preapical sternite (Fig. 1c) with deep cavity and a pair of spines in middle; apical sternite elongate, with median lobe oblong, surface deeply concave; aedeagus (Fig. 2c) without distinct rows of hairs. Length 7.5-12 mm ........wilcoxi, new species Elytra entirely brownish or reddish brown, without black margins. In male, preapical sternite without cavity and spines; apical sternite (Fig. 1b) not elongate, the median lobe transverse, concave; aedeagus (Fig. 2b) with rows of hairs. Length 9-13.5 mm unicolor Jacoby

\section{Coeligetes Jacoby}

Coeligetes Jacoby, 1884, Notes Leyden Mus. 6:227.- Wilcox, 1973, Col. Cat. Pars 78(3):447.- Seeno \& Wilcox, 1982, Entomography 1:111. Type: Coeligetes submetallica Jacoby.

Coeligethes Jacoby, 1893, Entomol. 26(Suppl.):102.- Seeno \& Wilcox, 1982, Entomography 1:111.

\section{Coeligetes unicolor Jacoby}

(Figs 1b, 2b)

Coeligetes unicolor Jacoby, 1895, Stett. Ent. Ztg. 56:80 (Java).

Specimens examined: Malaysia, Pahang, Tasik Chini, 12-14.v.1993, Zaidi, Ruslan \& Kamaruddin, UKM, 1. Perak, Tapah, Lat Iskandar, 27.ix.1986, Ismail, UKM, 1. Sabah, Taman Kinabalu, Poring, 9-12.xii.1990, Zaidi, Ismail \& Ruslan, UKM, 1; Gunung Kinabalu, Sayap, 3-8.vi.1992, Zaidi, Ismail \& Ruslan, UKM, 2. Lembah Danum, 17-20.iv.1992, Ismail, Yusuf \& Razali, 
UKM, 1; 22-25.vii.1992, Ismail, Yusuf \& Sham, UKM, 1; 5-8.xii.1992, Ismail, Yusuf \& Razali, UKM, 2. Sarawak, Lanjak Entimau, 22-29.ii.1992, Zaidi, UKM, 6.

Remarks. This is a new record for Peninsular Malaysia (Perak) and Borneo (Sabah, Sarawak). The color of the dorsal surface varies from yellowish in specimens from Peninsular Malaysia and Sabah to reddish brown in specimens from Sarawak.

\section{Coeligetes borneensis new species}

(Figs 1a, 2a)

Head reddish brown, except vertex blackish; longitudinal median furrow distinct from occiput to the base of fronto-clypeus; interocular space as broad as the transverse diameter of each oculus; fronto-clypeus with the transverse ridge elevated, triangular; labrum transverse, sparsely pubescent; maxillary palpi robust, the penultimate segment broadened and covered with long pubescence, the terminal segment narrower, conical. Eyes large, protuberant. Antennae very long, extending to apical one-fifth of the elytra; segment 1 longest, club-shaped; 2 shortest, twice as long as broad; 4 one and one-half times as long as 3;4-11 subequal in length. Pronotum reddish brown, transverse, 2.2 times as broad as long; anterior border broadly curved posteriorly; lateral borders rounded; posterior border sinuate in middle; surface convex, smooth. Scutellum black, smooth, longer than broad. Elytra metallic green, parallel-sided; surface densely covered with large punctures, rugose. Ventral surface reddish brown. Legs brownish, except tibiae with blackish streak at the outer sides. Posterior trochanter bearing long spine, half as long as the femur. Apical sternite (Fig. 1a) with median lobe oblong, its surface moderately deeply concave. Aedeagus (Fig. 2a) robust, with apical piece truncate at apex; dorsal hooks armed with rows of hairs. Length $11.5 \mathrm{~mm}$.

Female. Size slightly larger than male (Length 13-13.5 mm). Posterior trochanter without spine. Apical sternite deeply emarginate at apex.

HOLOTYPE. Male. MALAYSIA, Sabah, Taman Kinabalu, HQ, 25-27.v.1991, Zaidi, Ismail \& Ruslan (UKM).

PARATYPES. MALAYSIA, Sabah, Taman Kinabalu, HQ, 13-15.xii.1990, Zaidi, Ismail \& Ruslan, 7 females (UKM). 
One of the paratypes will be deposited in Museum of Comparative Zoology (MCZ), Harvard University, U.S.A.

Remarks. This species resembles Coeligetes submetallica Jacoby, but differs in having the male preapical sternite entire, without spines and cavity, and each of the posterior trochanters bears a long spine.

\section{Coeligetes wilcoxi new species}

(Figs 1c, 2c)

Head reddish; interocular space 1.2 times as broad as the transverse diameter of each oculus; fronto-clypeus triangular, elevated; frontal tubercles moderately raised, triangular, contiguous; maxillary palpi with terminal segments swollen. Eyes large, protuberant. Antennae long, extending to apical third of the elytra; segment 1 longest, club-shaped; 2 shortest, as long as broad; 3 slightly shorter than 4; 4-11 subequal in length. Pronotum reddish, transverse, 2.3 times as broad as long; anterior border broadly curved posteriorly; lateral borders rounded; posterior border sinuate in middle. Scutellum blackish, smooth, longer than broad. Elytra brownish, black on apical, sutural and lateral margins, with the latter broadly blackened; sides parallel; surface finely rugose, covered with small punctures. Ventral surface reddish brown. Legs yellowish, except tibiae with blackish streak at the outer sides. Preapical sternite (Fig. 1c) with deep cavity and a pair of spines in middle. Apical sternite elongate, 3 times as long as the preapical sternite, broadly and deeply concave in middle, the median lobe elongate, deeply concave. Aedeagus (Fig. 2c) with apical piece blunt at apex; dorsal hook without distinct hairs on its surface. Length $7.5 \mathrm{~mm}$.

Female. Size larger than male (11.5-12 mm). Apical sternite deeply emarginate at apex.

HOLOTYPE. Male. MALAYSIA, Selangor, Bukit Belachan, 24.ii.1990, Maklarin (UKM).

PARATYPES. MALAYSIA, Selangor, Bukit Belachan, 24.ii.1990, Nonna, Female (UKM); S. Abin, Female (UKM). Pahang, Kuala Lompat, 21-22.iii.1990, Salleh, Ismail \& Ruslan, Female (UKM). Pulau Tioman, Tekek, 22-28.iv.1993, Zabidi, Sham \& Razali, Female (UKM). Cameron Highlands, Tanah Rata, 15.x.1986, 
Ismail, Female (UKM). INDONESIA. Sumatra, Soekaranda, i.1894, Dohrn, Male (MCZ).

One of the paratypes from the UKM Collections will be deposited in Museum of Comparative Zoology (MCZ), Harvard University, USA.

Etymology. This species is named in honour of Dr. John A. Wilcox, Lancaster, Ohio, USA.

Remarks. This species resembles Coeligetes unicolor Jacoby, but differs in having the elytra black on the lateral, sutural and apical margins. The structure of the male apical sternites (Figs. 1b, 1c) and aedeagi (Figs. 2b, 2c) differs significantly between these species. 

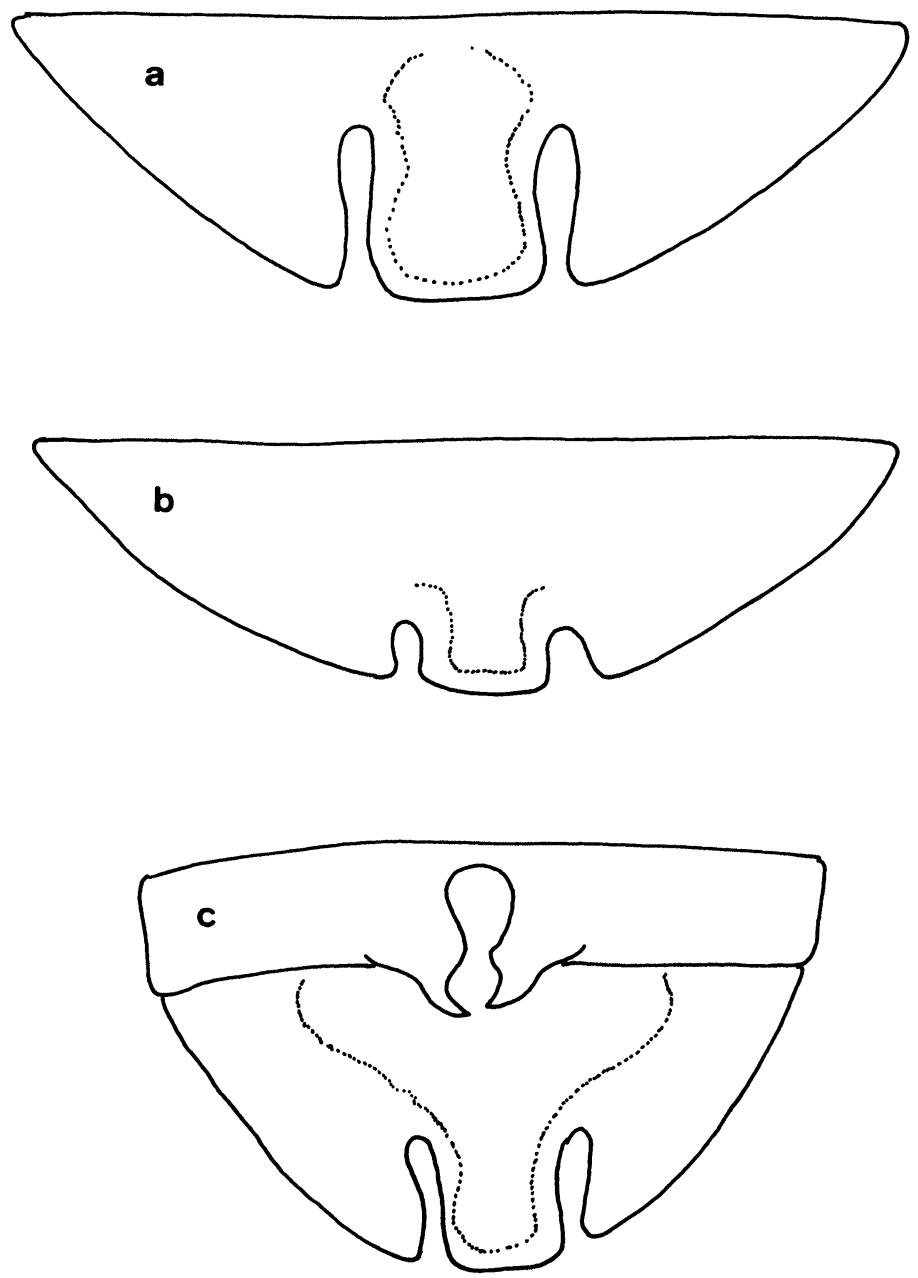

Figs 1a-b. Male apical sternites of Coeligetes.

a. Coeligetes borneensis

b. Coeligetes unicolor

c. Coeligetes wilcoxi 

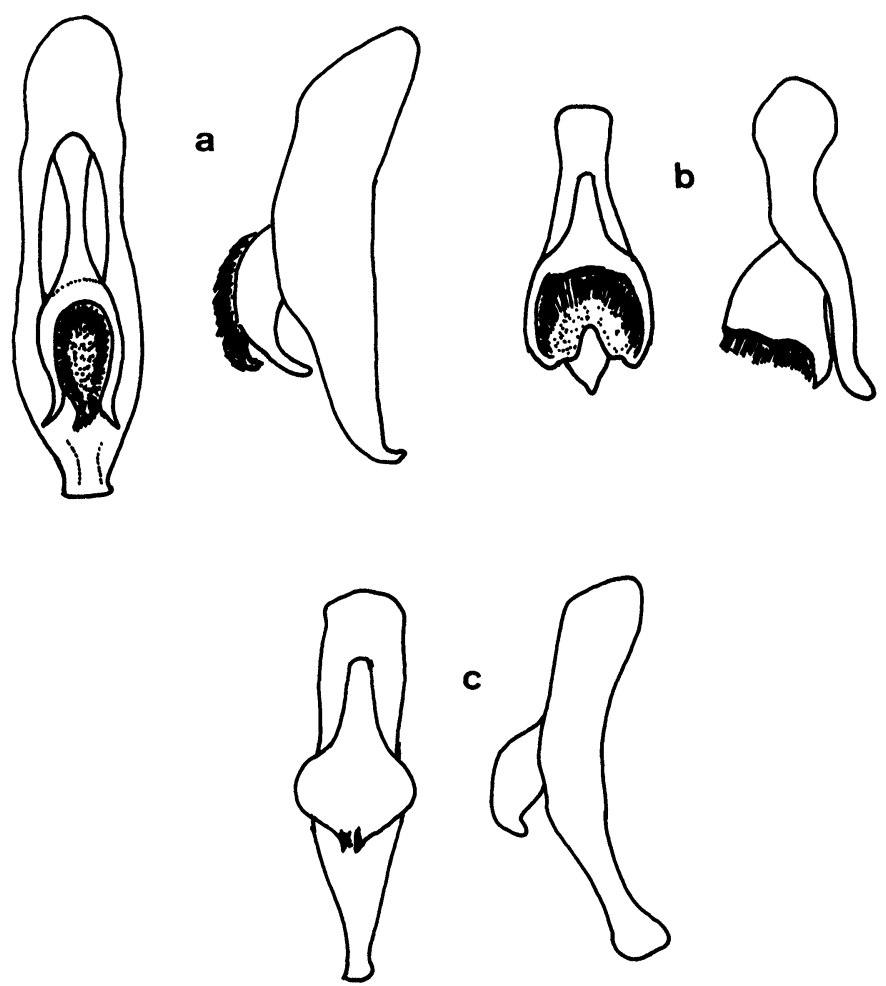

Figs 2a-c. Aedeagi of Coeligetes, dorsal and lateral views.

a. Coeligetes borneensis

b. Coeligetes unicolor

c. Coeligetes wilcoxi 


\section{ACKNOWLEDGMENTS}

Revisionary study on the Malaysian Chrysomelidae is supported by the IRPA Project No. 4-07-03-007, which is gratefully acknowledged. The author would like to thank the Ernst Mayr Grant Committee, Harvard University, for financial support enabling the author to visit the Museum of Comparative Zoology (MCZ), Harvard University, USA, to examine Jacoby's materials.

\section{REFERENCES}

Jacoby, M. 1884. Descriptions of new genera and species of phytophagous Coleoptera collected by Dr. B.Hagen at Serdang East Sumatra). Notes Leyden Mus. 6:201-230.

_ - 1893. Notes on some species of Galerucinae.Entomologist 26(Suppl.): 102-103.

1895. Descriptions of new species of phytophagous Coleoptera from the Indo and Austro-Malayan Region. Stettiner Ent. Ztg. 56:52-80.

Seeno, T.R. \& J.A. Wilcox, J. 1982. Leaf beetle genera (Coleoptera: Chrysomelidae). Entomography 1:1-221.

Wilcox, J.A. 1973. Coleopterorum Catalogus, Supplementa, Chrysomelidae: Galerucinae, pars 78(3):433-664 (Second Edition). 

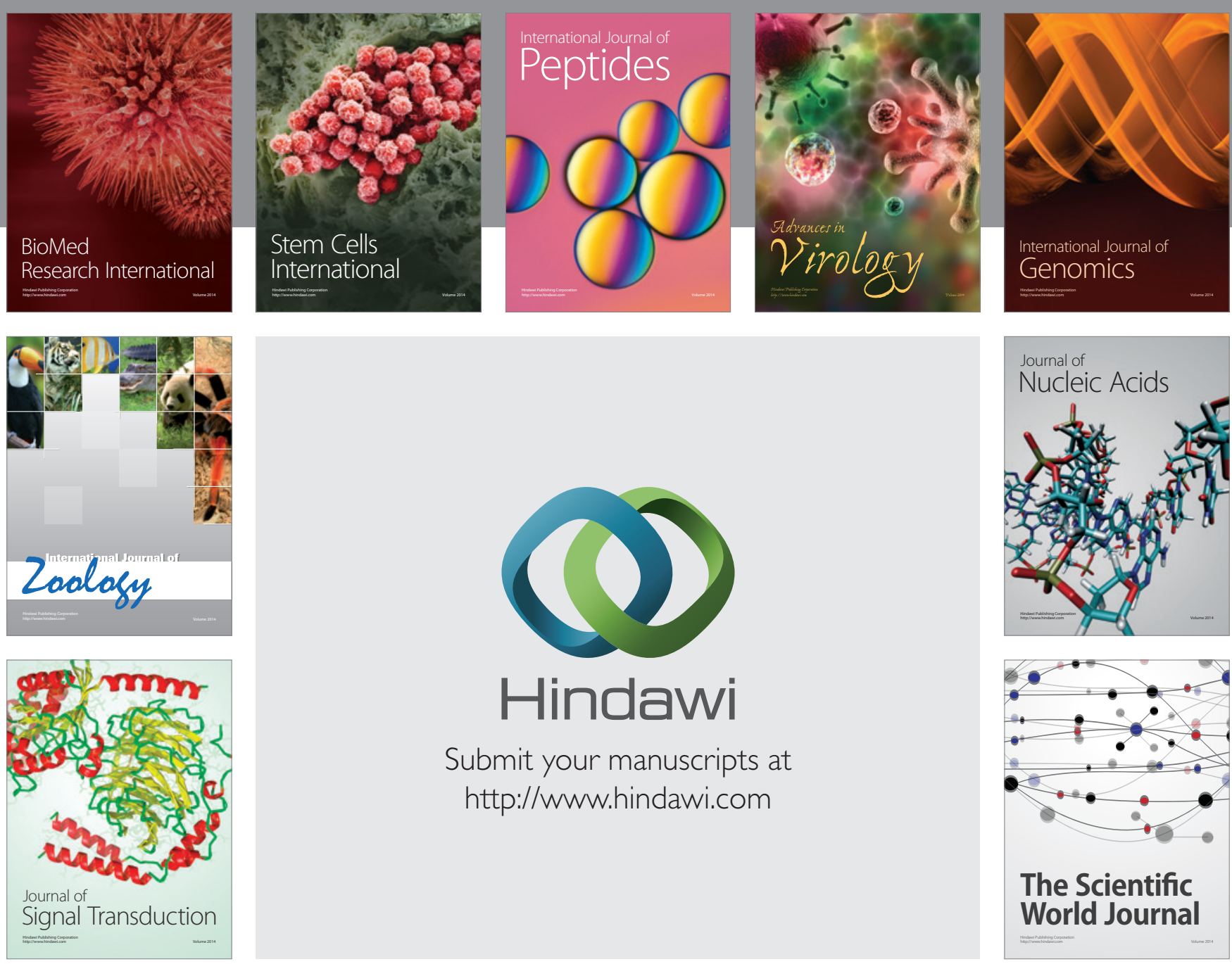

Submit your manuscripts at

http://www.hindawi.com
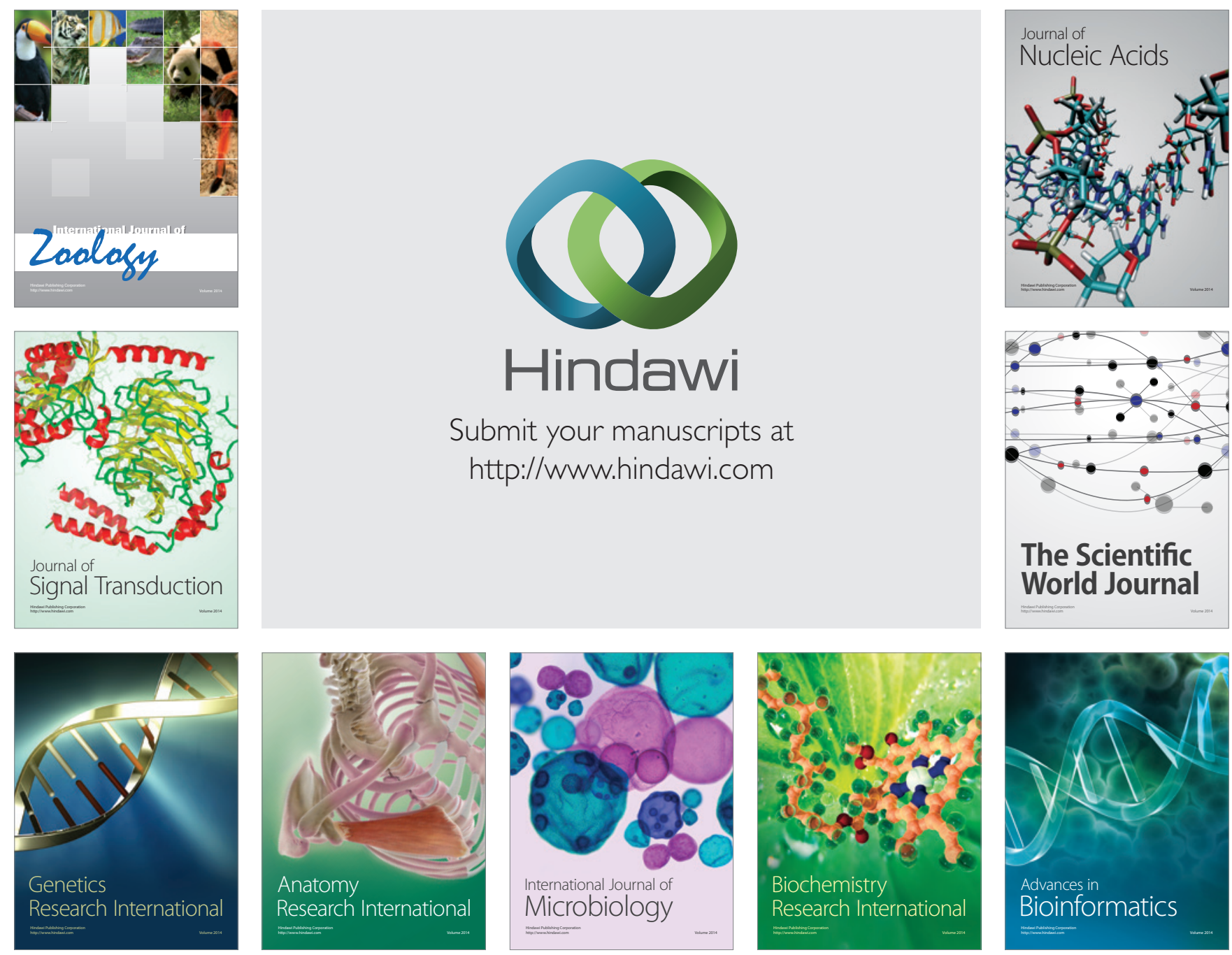

The Scientific World Journal
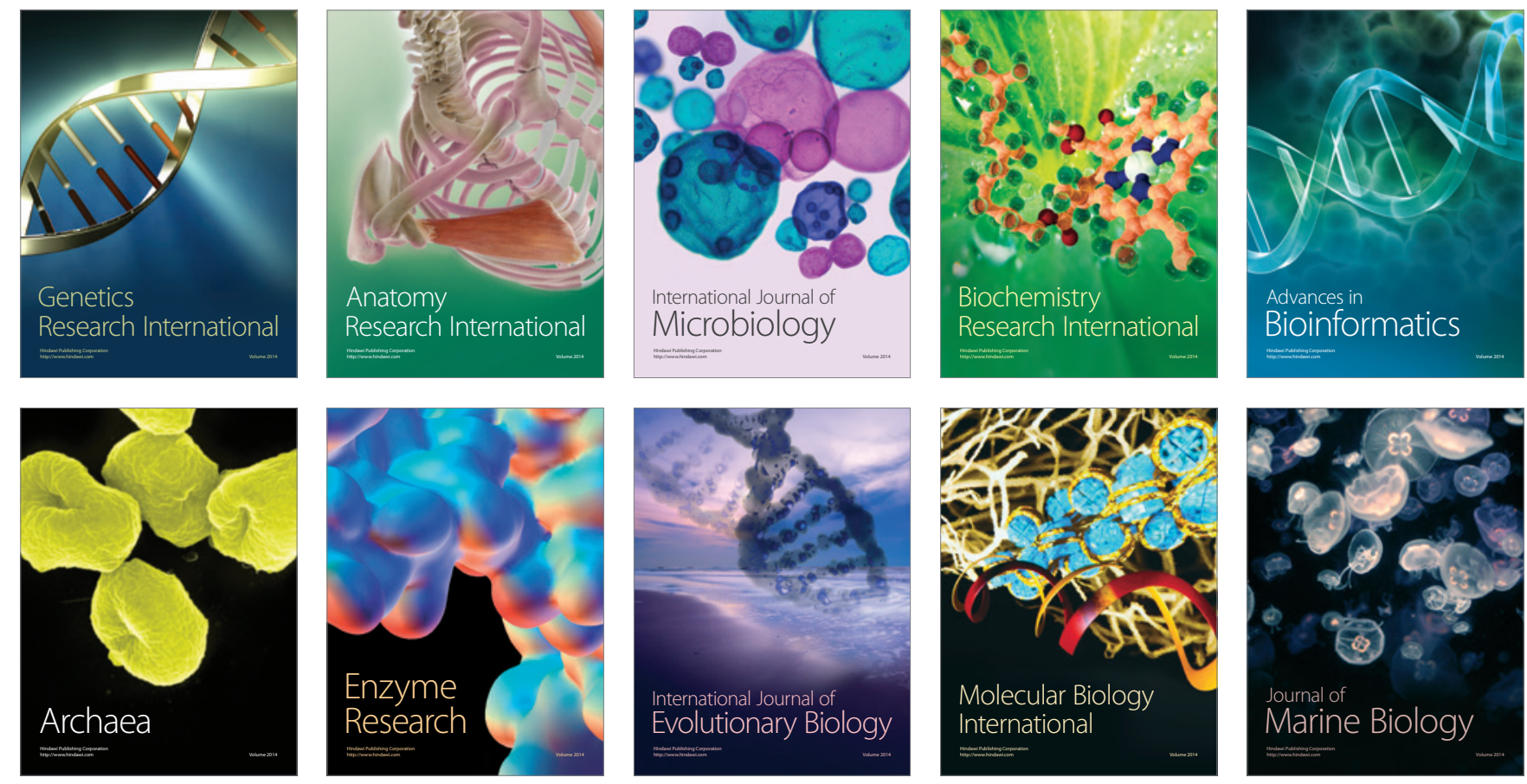